\title{
Medical missions for the provision of paediatric cardiac surgery in low- and middle-income countries
}

\author{
Frank J. Molloy, ${ }_{1}^{1}$ Nguyenvu Nguyen, ${ }^{2}$ Marisa Mize, ${ }^{3,4}$ Gavin Wright, ${ }^{5,6}$ Cecilia St. George-Hyslop, ${ }^{7,8}$ \\ Maura O'Callaghan, ${ }^{9}$ Emma Scanlan, ${ }^{6}$ William M. Novick ${ }^{1,10}$ \\ ${ }^{1}$ William Novick Global Cardiac Alliance, Memphis, Tennessee; ${ }^{2}$ Pediatric Cardiac Intensive Care, Banner Children's, \\ Cardon Children's Medical Center, Mesa, Arizona; ${ }^{3}$ Por Cristo, Boston, Massachusetts; ${ }^{4}$ Pediatric Critical Care, \\ Children's National Medical Center, Washington, District of Columbia, United States of America; ${ }^{5}$ Critical Care and \\ Anaesthesia, Royal Brompton and Harefield NHS Foundation Trust, London; ${ }^{6}$ Chain of Hope, London, United Kingdom; \\ ${ }^{7}$ Cardiac Critical Care Unit, Hospital for Sick Children, Labatt Family Heart Centre, Toronto; ${ }^{8}$ University of Toronto, \\ Toronto, Canada; ${ }^{9}$ Cardiac Critical Care and Respiratory Division, Great Ormond Street Hospital NHS Foundation \\ Trust, London, United Kingdom; ${ }^{10}$ Surgery and International Child Health, University of Tennessee Health Science \\ Center, Memphis, Tennessee, United States of America
}

\begin{abstract}
This review will outline the role of visiting cardiac surgical teams in low- and middle-income countries drawing on the collective experience of the authors in a wide range of locations. Requests for assistance can emerge from local programmes at a beginner or advanced stage. However, in all circumstances, careful pre-trip planning is necessary in conjunction with clinical and non-clinical local partners. The clinical evaluation, surgical procedures, and postoperative care all serve as a template for collaboration and education between the visiting and local teams in every aspect of care. Education focusses on both common and patient-specific issues. Case selection must appropriately balance the clinical priorities, safety, and educational objectives within the time constraints of trip duration. Considerable communication and practical challenges will present, and clinicians may need to make significant adjustments to their usual practice in order to function effectively in a resource-limited, unfamiliar, and multilingual environment. The effectiveness of visiting trips should be measured and constantly evaluated. Local and visiting teams should use data-driven evaluations of measurable outcomes and critical qualitative evaluation to repeatedly re-assess their interim goals. Progress invariably takes several years to achieve the final goal: an autonomous self-governing, self-financed, cardiac programme capable of providing care for children with complex CHD. This outcome is consistent with redundancy for the visiting trips model at the site, although fraternal, professional, and academic links will invariably remain for many years.
\end{abstract}

Keywords: CHD; international medicine; non-governmental aid organisations

Received: 15 September 2017; Accepted: 15 September 2017

$\mathrm{P}$ OOR ACCESS TO PAEDIATRIC CARDIAC SURGICAL interventions in low- and middle-income countries represents a large unaddressed disease burden, with around $90 \%$ of those one million born annually with CHD having no access to affordable

Correspondence to: F. J Molloy, RN, MSc, ANP, Novick Cardiac Alliance, 1750 Madison Avenue, Suite 500, Memphis, TN 38104, United States of America. Tel: +1 901302 9500; Fax: +1 901302 5000; E-mail: frank.molloy@cardiac-alliance.org specialist surgical treatment. ${ }^{1-4}$ This fits within a wider issue of healthcare delivery: mainly five billion of the world population having no access to safe and affordable general surgical care.

In the past, a variety of philanthropic nongovernmental organisations in host countries responded by providing individual sponsorship of children for surgical treatment abroad. It was quickly realised that sending in a cardiac surgical team to 
operate on 10-20 children in the host country referred to as a "trip" - could be accomplished for the same cost as sending one child abroad. ${ }^{\text {.-9 }}$

Visiting teams generally comprise between five and 20 professionals per trip, including clinicians from anaesthesia, cardiac surgery, perfusion, cardiology, nursing, and ICU staff. A variety of models exist, with variations in frequency, duration, team size, and levels of clinical involvement. ${ }^{10}$ Medical teams have been variously described as "camps", "mentoring trips", "brigades", "workshops", or "missions", the last of these having been commonly associated with religious organisations. ${ }^{11}$

\section{Trip goals}

The primary goal of trips is to assist in developing a successful autonomous self-governing, self-financed cardiac programme capable of providing care for children with complex CHD with little or no further need for visiting assistance. Over time, the visiting team becomes obsolete. ${ }^{12}$

A trip is, by its nature, a collaborative participation with local professionals that aims to demonstrate the direct provision of paediatric cardiac surgery successfully in the local centre, and compare results with international standards. This differs distinctly to a didactic, academic, or virtual teaching experience as the patient pathway forms the majority of the template for education. Learning opportunities arise from every real-life or simulated clinical experience.

The centre, comprising a team of individuals in a location, is expected to undergo changes itself. Changes occur through team training and growth, or with facilities development, throughout phases of programme maturation.

On the route towards visiting team obsolescence, operations between trips should begin, or increase in numbers, consolidating what is experienced on trips. Complexity and case volume are expected to increase over time, $, 10,13,14$ and patient age and size decrease as the collaboration develops. The proportion and number of surgical operations performed during trips decreases. $^{15}$

\section{Design and planning}

Local clinical partners are an essential prerequisite, and must include a minimum of a cardiologist and surgeon providing patient assessment, communication, and long-term follow-up. A full clinical team may not always exist with the commencement of new programmes, ${ }^{16}$ but should form an early objective. Requests for assistance vary by host centre characteristics, ranging from new sites with minimal cardiac surgical experience to established sites seeking to improve on results in high-risk, lowweight critical defects. ${ }^{14,17}$

Additional partners in the native environment, knowledgeable of the local political, logistical, and financial complexities, may be governmental, civic, or local non-governmental organisations. ${ }^{12}$ Their role is supporting public relations, locally based fundraising, assisting with visas, importing supplies, professional team clearance, and essential aspects of communications.

Lists of minimum supplies, infrastructure, drugs, and equipment should be sent in advance, and a visit by a core team including a biomedical engineer along with one to two other clinicians is critical when establishing a new site. For sites where cardiac surgery is already being performed, direct evaluation may not be necessary, although later biomedical engineering support is frequently useful for local training, identifying unmet needs, and optimising equipment usage.

Infrastructure evaluation for a new site should include assessment of echocardiography facilities, cardiac catheterisation laboratory, operating theatre, ICU, radiology, blood transfusion, laboratory medicine, and pharmacy services. Biomedical engineering support may be necessary to further evaluate infrastructure issues such as gas, suction, power supply, and generators.

Hospitals may be able to donate used equipment for trips. Non-functional donated equipment is a commonly cited problem; one study estimated that $\sim 40 \%$ of donated equipment in low- and middleincome countries is unusable. ${ }^{5,18}$ Donors may need reassurance that the recipients take biomedical and clinical responsibility for subsequent placement in use. It may be appropriate to temporarily bring smaller items such as pacemakers and portable blood gas analysers, if acuity or surgical numbers on a trip exceeds usual local capacity.

A functional pharmacy is essential for a hospital aspiring to perform paediatric cardiac surgery, and a full list of drug availability is sought. The authors do not advocate importing out-of-date medications as donations. Evidence of stability may, however, form the basis of local clinical decisions subject to regulations and practice. ${ }^{19}$ The World Health Organization $^{20}$ essential medicines list for children may be used as a template of need or donation list for new or adult sites for any additional items to specialist cardiac medications.

Supplies, including disposables, may be sought for donation. Organisations exist to receive and distribute unused functional medical items, although it should not be considered as a sustainable solution for items that are high volume, used every day, and for single use. Functionally multiuse external contact 
items, which are able to be cleaned, such as resuscitation bags, masks, blood pressure cuffs, or oxygen tubing, may be more beneficial. Guidance exists on reuse of single-use items; ${ }^{21,22}$ however, local experience, regulations, context, and safety are paramount.

Donations of any category should not be made without an agreed upon need. Local medical supply is an economy that should be engaged and is essential for sustainability.

Initial trip frequency may be planned based upon the needs, experience, and opinions of local partners along with an evaluation of the facility. Information is generally gained after the first trip for future planning. Team composition and size should focus on the specific clinical and educational needs of the site, ability to speak the local language, clinical expertise, and prior trip experience, all of which are important factors in team recruitment and selection.

\section{Patient assessment and scheduling}

A balanced caseload on any trip involves competing priorities and difficult decisions. Case scheduling must take account of issues such as clinical need, programme success, duty-of-care obligations, team learning, and ICU workload.

Multi-disciplinary case conferences should commence with every trip. Scheduling lower-acuity, older patients in the first 1-2 days of any visit may reveal latent failures and communication difficulties, ${ }^{23,24}$ while minimising risk in comparison with operating on smaller, critically ill infants.

The prevalence of "simple" defects and non-critical surgical cases may be higher in a country with a prior surgical deficit. ${ }^{25,26}$ These cases may lead to confidence building, serve larger numbers with better outcomes, maintain regular team practices, and may be an early educational objective for operating independently in new sites. Morale and programme success could be threatened by multiple, early mortalities even within risk-adjusted international standards.

Nevertheless, critically ill patients who have no other national or international options are more likely to die if declined for surgery, and may take up valuable ICU resources regardless of surgical decisionmaking. If there is an acceptable chance of success, these patients may be considered for surgery subject to local system and training issues. Persistent avoidance of difficult cases limits the training exposure of the local staff, ${ }^{27}$ despite the fact that challenging cases will continue to present. Teams who visit two to four times annually may be better prepared to take on more complex cases especially when staged procedures are considered. ${ }^{28}$

No one strategy or case-mix type can be recommended, as programmes seek assistance at varying stages of development. A clear plan should be part of a shared, agreed upon agenda between the visiting and local team, and be reviewed at least annually.

\section{Team approach}

Side-by-side training for all specialties is crucial to sustainable success. ${ }^{1,29}$ No visiting clinician should be practicing without a local counterpart, and risks should be discussed pre-emptively on a "what if" basis. If an emergency mandates a fast intervention that cannot be contemporaneously explained, dedicated time should be set aside after the event to debrief the process with the local clinicians involved.

Visiting team members should recognise potential communication challenges and risks posed by their presence. Measures to simplify and verify essential communications are paramount. Verification of understanding regarding aspects of cardiac surgical management is prone to error, even between English speakers. "Yes" and "no" questions should not be asked as the answer "yes" might simply mean "I am listening to you". Translators from language departments of local universities may be useful; however, suitable translation assistance is usually available from within the medical field.

Documentation, including drug prescription, should be in the native language as possible, and written by the local team without disruption of the established systems. Further recommendations include use of generic drug names, locally used units of measurement, avoidance of abbreviations and jargon, and communicating visually, diagrammatically, and in proximity to the issue of discussion.

Exact locations of emergency equipment, and specifications for prepared emergency scenarios, should be addressed at the beginning of a trip in each clinical area and preparations agreed upon with local teams.

\section{Operation theatre and cardiac catheterisation laboratory}

Anaesthetists may be required in both the operation theatre and the cardiac catheterisation laboratory. Local anaesthesia staff may have sufficient expertise to cover catheterisation laboratory procedures, although priority should be given to their presence during surgery for teaching cases. The potential for simultaneous emergencies requires appropriate preparation by the team, and may necessitate intervention by ICU staff trained in airway, anaesthesia, and sedation management.

Protocolised practices such as pre-procedural check lists, ${ }^{31,32}$ care and monitoring during transfer, and structured handover from operating theatre to $\mathrm{ICU}^{33,34}$ should be used regardless of complexity. 
Anaesthetic machines must specifically be checked for paediatric ventilation capability. Capnography in ICU or operating theatre is essential, low cost, and can reduce blood gas analyses. Training in vascular ultrasound may also be useful. ${ }^{35,36}$

Blood availability is often poor. ${ }^{37}$ Patients' families are potential donors, but may pose associated risks of graft-versus-host reactions. ${ }^{38,39}$ Viruses and parasitic infections - such as malaria and American trypanosomiasis - are additional risks of blood transfusions. ${ }^{40,41}$ Patients may present with preoperative anaemia - for example, due to helminth infection - requiring treatment, and proactive iron supplementation can be useful in raising haemoglobin. ${ }^{42,43}$ Agents for haemostasis such as tranexamic acid or aprotinin may also reduce blood transfusion requirements. ${ }^{44}$ Restriction of blood product transfusions owing to high risks of locally related factors may be the best strategy. ${ }^{45-47}$ Established blood product identification and safety checking processes by local clinicians help to reduce error associated with blood transfusions. Coombs testing is a useful additional safety measure.

Basic transoesophageal echocardiography skills can be taught, and further education and training should be encouraged to develop skills. ${ }^{48}$ Intraoperative epicardial echocardiography is a useful alternative ${ }^{49}$ as a learning tool for the adequacy of repair, and may improve identification and success rate of operative revision when compared with identifying residual lesions later. ${ }^{50}$

Local surgeon teaching is dependent upon the experience they have when the visiting team arrives. Providing a list of previous surgeries performed with results will give the visiting surgeon some knowledge of the level of local capability. It may be ideal to begin with procedures the host surgeon is capable of performing under the guidance of the visiting surgeon. This allows for an assessment of skill level by the visiting surgeon and serves as a guide for advancing the level of complexity under mentorship as appropriate. One should not ask a local surgeon to perform a case that they do not feel comfortable performing, even with the visiting surgeon's assistance. Graduated development that builds confidence, competence, and skill is key. ${ }^{51}$ The visiting surgeon may be faced with defects and complications of longstanding CHD and should be prepared to be flexible and innovative. ${ }^{52-56}$

Ultra-fast-track anaesthetic technique is the general goal geared towards early extubation. ${ }^{57}$ Normothermic strategies during or post-bypass and use of warm air blowers assist in early extubation. ${ }^{58,59}$ Fast-tracking reduces exposure to morbidity and mortality from failures of equipment, power, or gas, or ICU nursing presence or experience. Additional benefits include reductions in ICU sedation and inotrope requirements, ventilator-associated pneumonia, and ICU and hospital stay. ${ }^{60-62}$

\section{Teaching and practice}

A visiting ICU team briefing and orientation is essential. Team members may have heterogeneous medical backgrounds or humanitarian medicine experiences. Before each trip, it is important that all members have a shared understanding of the general approach, availability and limitations of equipment and local protocols, communication, emergency preparedness, and risk reduction practices. Risk reduction measures such as distraction-free drug preparation practices, ${ }^{63}$ and the checklist or "time out" approach before ICU procedures, such as extubation or chest drain removal, are encouraged. ${ }^{64}$

A trained paediatric cardiac intensivist is a rarity, and other specialties fill this role including cardiac surgeons, anaesthetists, and cardiologists. ${ }^{65}$ It may be a challenge to clearly identify local ICU medical leadership.

A paediatric cardiac ICU nursing team may emerge from a basis of adult or paediatric experience, but a subset of nurses may need to be identified for paediatric specialisation and education. ${ }^{66}$

Didactic teaching typically focusses on common issues such as infection control, bleeding, postoperative care, pain management, and arrhythmia control. In-depth training should also focus on planned surgical cases to include discussion of anatomic defects, pathophysiology, postoperative haemodynamics, and expected complications. Onsite education can be in the format of cardiac catheterisation conferences or short informal bedside settings that are embedded into routine workflow for ICU personnel. Educational needs of local night staff may need specific additional consideration if unable to attend daytime training.

Collaborative rounding with the multidisciplinary team should involve host team members presenting clinical data, using the local language. Assessment and plans should be jointly developed, and all key points fully translated. These rounds, either led by a physician or nurse, are a core part of the training approach. Other communication events in the ICU, such as shift-to-shift handover, and patient admission from theatre, should have a similar clear structure, and not be interrupted. The practice of listening without extraneous conversations or telephones should be role-modelled by visiting ICU team members.

Local clinicians may feel overwhelmed by the presence of a visiting team and the new experience of providing care to children after open-heart surgeries. They may be hesitant to exhibit leadership during 
resuscitation or lead discussions to develop patient recovery plans. For the visiting team, it is critical to avoid going into the immediate "takeover" problemsolving mode during these circumstances. Instead, clinicians from both sides should partner closely, develop shared communication and understanding, to arrive at plans to address the clinical problems.

\section{Problems and risks}

Teams must always recognise that their presence may create safety risks. The team is inherently disruptive. Disruption is positive if it modifies unsafe practices and encourages growth, but negative if it removes embedded safety practices. Critical examples might include introducing drugs of a different concentration to local supplies, or creation of a surgical list plan that bypasses an embedded system designed to identify the correct patient at the correct time. Safety may be compromised by local teams not accustomed to the large number of cases attempted in a short trip, and this affects other specialties that use the same facilities.

In some sites, parental presence in the ICU may be prohibited. Teams have an ability to promote this and other cultural changes in ICU, although progress may be small and incremental, as with many changes. Variations in usual roles and practice models by the visiting team that are atypical to the clinical setting must be negotiated into a practice consistent with local regulations and programme objectives.

Many practical and often unexpected difficulties may be encountered. This may include lack of emergency cylinders requiring self-inflation bags, and use of 42-l oxygen "pillows" for short inter-departmental transfers. ${ }^{67}$ Adaptability is an essential characteristic on a trip. Visiting teams not only provide education but often learn from host teams in limited resource settings. Examples include central venous catheters used as pleural or peritoneal drainage devices, or ICU-prepared dialysis solutions. Nitric oxide is often prohibitively inexpensive or inaccessible, although sildenafil is generally more available. ${ }^{68}$ Strategies for pulmonary hypertension management need to be discussed within local resources.

Parity with the best equipment standards may be an aspiration, but learning to operate within locally existing resources, with appropriately tailored case selection, is a priority of a visiting team. ${ }^{69}$ Improvements can be incremental and may follow early successes.

Teams may find themselves as part of a multiorganisational approach characterised by different styles in care management. Liaison and co-ordination between teams is recommended, ${ }^{70}$ and brings a stronger and more successful project to maximise consistency and share insights on progress.
Cases with specific needs such as conduits or valves should be presented well before a trip to allow procurement or donation.

A paradox of the paediatric cardiac literature is that the majority is written in $10 \%$ of the world that has the full range of services, and not in the $90 \%$ that is still underdeveloped. ${ }^{71}$ Stages of presentation, available treatments, and comorbidities differ greatly, and a humble and cautious non-didactic application of one's own knowledge and experience is often useful.

Teams that undertake high-complexity cases may need to have a core team stay behind for a week after the final surgery to provide the local team with support to address potential ICU complications. Application-based tele-conferencing can complement the visiting model, with post-trip consultation and communications made easier by personal familiarity, professional respect, and trust.

\section{Insurance, licensing, and liability}

The occurrence of lawsuits against visiting teams vary in the literature, and range from one per 1000 cases to none in over 8500 cases. $^{72}$ Even a failed lawsuit incurs significant costs. Obtaining direct permission from the relevant regional or national ministry of health through liaisons with governmental agencies and local partners is strongly advised. ${ }^{73}$ This is not always the same as licensing, as fluency in local language is necessary to be accepted formally into the professional register of many countries. Malpractice insurance specifically designed for volunteer trip practice is available through many providers, and may already be included in standard policies. ${ }^{74}$

\section{Outcomes and benefits}

Humanitarian outcomes using number of children operated, combined with short stories and photos for viewing by a non-professional audience, are a useful way to present the humanitarian impact of a programme. Presenting these data to a governmental or charitable donor-funding agency may help to ensure continued funding and avoiding costs associated with sending children to other countries for surgery. Infrastructure upgrades, donations of equipment, supplies, and medications impact humanitarian outcomes by providing some of the needs for on-going programme development.

Data collection is a key prerequisite to any audit and reporting of clinical outcomes. Organisations that support multiple sites must be able to collect and analyse their own data as issues may occur across sites.

Data collection by the local sites should be required $^{75}$ because the clinical outcomes of the programme extend beyond the humanitarian count of 
"number of children saved". ${ }^{76}$ The ability to collate riskadjusted, age-stratified mortality and selected morbidity analyses $^{77}$ can demonstrate programme growth, the impact of the trips, and inform planning for on-going site support. Sites are encouraged to participate in international data and quality initiatives. ${ }^{18-81}$

Educational outcomes are difficult to directly measure. A useful measure of surgical outcome is the proportion and type of surgeries performed by the local operators during trips. Additionally, data on surgeries between trips, when combined with mortality and morbidity analysis, ${ }^{76}$ can help demonstrate whole team growth when a trip team is not present. ${ }^{15}$

Trip team size usually reduces over time as the local team develops. This enables continued support while reducing cost, until eventually team visits are no longer needed.

Continuing education locally for all healthcare professionals can be maintained aside from and after team trip visits. ${ }^{82}$ Host centre staff can be used as team volunteers to other sites as expertise improves. Academic and supportive links (twinning) ${ }^{1,75}$ are generated by visiting teams who frequently invite local professionals to visit, may share journal articles that are not accessible locally, or sponsor conference attendances and manuscripts, or conference abstract presentations. Many sites in low- and middle-income countries may have no access to well-resourced library facilities. Thus, many papers, identified as core essential reading, ${ }^{83}$ are not available. Medical trips are thus one route to bridging academic isolation.

\section{Conclusions}

The visiting trips model focusses on real-world solutions where visiting teams and local staff together train and work collaboratively to achieve the best possible clinical outcomes. The central objective is for the local teams themselves to be able to achieve the same outcomes, without the assistance of visiting trips. The obsolescence of the visiting trips is the ultimate measure of their success.

\section{Acknowledgements}

The authors acknowledge and thank the many professionals worldwide who have welcomed them into their institutions for their support, hospitality, trust, collaboration and understanding - through whom we have learned, as we have taught. They further thank all the volunteers, sponsors and donors without whom they could not function.

\section{Financial Support}

William Novick was supported partially by the Paul Nemir, Jr., M.D. Endowed Professorship in International
Child Health at the University of Tennessee Health Science Center during the preparation of this manuscript. Frank Molloy has previously received product discount prior to the preparation of this manuscript from a commercial supplier referenced in citation 67 . The product is listed as illustrative only, of relevant professional interest, without specific recommendation - and many other suppliers exist.

\section{Conflicts of Interest}

None.

\section{References}

1. Dearani JA, Neirotti R, Kohnke EJ, et al. Improving pediatric cardiac surgical care in developing countries: matching resources to needs. Semin Thorac Cardiovasc Surg Pediatr Card Surg Annu 2010; 13: 35-43.

2. Cox J. Presidential address: changing boundaries. J Thorac Cardiovasc Surg 2001; 122: 413-418.

3. Yankah C, Fynn-Thompson F, Antunes M, et al. Cardiac surgery capacity in Sub-Saharan Africa: Quo Vadis? Thorac Cardiovasc Surg 2014; 62: 393-401.

4. Penny D. Global perspectives on pediatric cardiac critical care. Pediatr Crit Care Med 2016; 17: S388-S393.

5. Meara J, Leather A, Hagander L, et al. Global surgery 2030: evidence and solutions for achieving health, welfare, and economic development. Lancet 2015; 386: 569-624.

6. Sitkin N, Farmer D. Congenital anomalies in the context of global surgery. Semin Pediatr Surg 2016; 25: 15-18.

7. Nicholls M. Chain of hope - in European perspectives in cardiology. Circulation 2006; 114: f134.

8. Novick WM, Stidham GL, Karl TR, et al. Are we improving after 10 years of humanitarian paediatric cardiac assistance? Cardiol Young 2005; 15: 379-384.

9. Bayés de Luna A. International cooperation in world cardiology: the role of the World Heart Federation. Circulation 1999; 99: 986-989.

10. Nguyen N, Jacobs JP, Dearani JA, et al. Survey of nongovernmental organizations providing pediatric cardiovascular care in low- and middle-income countries. World J Pediatr Congenit Heart Surg 2014; 5: 248-255.

11. Butler M. Developing pediatric surgery in low- and middle-income countries: an evaluation of contemporary education and care delivery models. Semin Pediatr Surg 2016; 25: 43-50.

12. Novick W, Karl T. Dr William Novick (Founder and Medical Director of International Children's Heart Foundation), speaks to associate editor Dr Tom R. Karl. Cardiol Young 2014; 25: $1-7$.

13. Novick W, Stidham G, Karl T, et al. Paediatric cardiac assistance in developing and transitional countries: the impact of a fourteen year effort. Cardiol Young 2008; 18: 316-323.

14. Baliulis G, Lipnevičius A, Sudikiene R, et al. Sustainable knowledge transfer in pediatric cardiac surgery. World J Pediatr Congenit Heart Surg 2011; 2: 225-230.

15. Polivenok I, Nokhrin A, Molloy F, et al. Development of sustainable pediatric heart surgery program with international assistance model in two centers: 5 years results. J Cardiothorac Surg 2013; 8: O265.

16. Cohen AJ, Tamir A, Houri S, et al. Save a child's heart: we can and we should. Ann Thorac Surg 2001; 71: 462-468.

17. Dearani J, Jacobs J, Bolman M, et al. Humanitarian outreach in cardiothoracic surgery: from setup to sustainability. Ann Thorac Surg 2016; 102: 1004-1011. 
18. Perry L, Malkin R. Effectiveness of medical equipment donations to improve health systems: how much medical equipment is broken in the developing world? Med Biol Eng Comput 2011; 49: 719-722.

19. Cantrell LC, Suchard JR, Wu A, et al. Stability of active ingredients in long-expired prescription medications. Arch Intern Med 2012; 172: $1685-1686$.

20. World Health Organization. WHO model list of essential medicines for children, 2015. $5^{\text {th }}$ edn. Retrieved May 26, 2017, from http://www.who.int/medicines/news/eml_2015/en/.

21. Medicines and Healthcare Products Regulatory Agency. Single-use medical devices: implications and consequences of reuse, $\mathrm{v} 2.1,2 \mathrm{nd}$ ed 2013. Retrieved November 19, 2017, from https://www.gov. uk/government/publications/single-use-medical-devices-implicationsand-consequences-of-re-use.

22. Pantos I, Efstathopoulos EP, Katritsis DG. Reuse of devices in cardiology: time for a reappraisal. Hellenic J Cardiol 2013; 54: 376-381.

23. Reason J. Safety in the operating theatre - part 2: human error and organisational failure. Qual Saf Health Care 2005; 14: 56-60.

24. de Leval M, Carthey J, Wright D, Farewell V, Reason J. Human factors and cardiac surgery: a multicenter study. $\mathrm{J}$ Thorac Cardiovasc Surg 2000; 119: 661-672.

25. Bernier P-LL, Stefanescu A, Samoukovic G, Tchervenkov CI. The challenge of congenital heart disease worldwide: epidemiologic and demographic facts. Semin Thorac Cardiovasc Surg Pediatr Card Surg Annu 2010; 13: 26-34.

26. Mohammad N, Shaikh S, Memon S, Das H. Spectrum of heart disease in children under 5 years of age at Liaquat University Hospital, Hyderabad, Pakistan. Indian Hear J 2014; 66: 145-149.

27. Gathuya ZN. Pro: pediatric anesthesia training in developing countries is best achieved by selective out of country scholarships. Pediatr Anesth 2009; 19: 42-44.

28. Brooks A, Geldenhuys A, Zuhlke L, Human P, Zilla P. Pulmonary artery banding: still a valuable option in developing countries? Eur J Cardiothorac 2012; 41: 272-276.

29. Salas E, Almeida SA, Salisbury M, et al. What are the critical success factors for team training in health care? Jt Comm J Qual Patient Saf 2009; 35: 398-405.

30. Catchpole K. Task, team and technology integration in the paediatric cardiac operating room. Prog Pediatr Cardiol 2011; 32: 85-88.

31. Wahr J, Prager R, Abernathy JH, et al. Patient safety in the cardiac operating room: human factors and teamwork: a scientific statement from the American Heart Association. Circulation 2013; 128: 1139-1169.

32. Clark S, Dunning J, Alfieri O, et al. EACTS guidelines for the use of patient safety checklists. Eur J Cardiothorac 2012; 41: 993-1004.

33. Catchpole KR, de Leval MR, McEwan A, et al. Patient handover from surgery to intensive care: using Formula 1 pit-stop and aviation models to improve safety and quality. Paediatr Anaesth 2007; 17: 470-478.

34. Joy B, Elliott E, Hardy C, Sullivan C, Backer C, Kane J. Standardized multidisciplinary protocol improves handover of cardiac surgery patients to the intensive care unit. Pediatr Crit Care Med 2011; 12: 304-308.

35. Hosokawa K, Shime N, Kato Y, Hashimoto S. A randomized trial of ultrasound image-based skin surface marking versus real-time ultrasound-guided internal jugular vein catheterization in infants. Anesthesiology 2007; 107: 720-724.

36. Kantor D, Su E, Milliren C, Conlon T. Ultrasound guidance and other determinants of successful peripheral artery catheterization in critically ill children. Pediatr Crit Care Med 2016; 17: 1124-1130.

37. Doherty C, Holtby H. Pediatric cardiac anesthesia in the developing world. Pediatr Anesth 2011; 21: 609-614.
38. Thaler M, Shamiss A, Orgad S, et al. The role of blood from HLAhomozygous donors in fatal transfusion-associated graft-versus-host disease after open-heart surgery. N Engl J Med 1989; 321: 25-28.

39. Kopolovic I, Ostro J, Tsubota H, et al. A systematic review of transfusion-associated graft-versus-host disease. Blood 2015; 126 : 406-414.

40. Tambyah PA, Koay ES, Poon ML, Lin RV, Ong BK. Dengue hemorrhagic fever transmitted by blood transfusion. $\mathrm{N}$ Engl J Med 2008; 359: 1526-1527.

41. Dhingra N, Hafner V. Safety of blood transfusion at the international level. The role of WHO. Transfus Clin Biol 2006; 13: 200-202.

42. Awasthi S, Bundy D. Intestinal nematode infection and anaemia in developing countries. BMJ 2007; 334: 1065-1066.

43. Wright I, Walker I, Yacoub M. Specialist surgery in the developing world: luxury or necessity? Anaesthesia 2007; 62: 84-89.

44. Schouten ES, van de Pol AC, Schouten AN, Turner NM, Jansen NJ, Bollen CW. The effect of aprotinin, tranexamic acid, and aminocaproic acid on blood loss and use of blood products in major pediatric surgery: a meta-analysis. Pediatr Crit Care Med 2009; 10: 182-190.

45. de Gast-Bakker DH, de Wilde RPB, Hazekamp MG, et al. Safety and effects of two red blood cell transfusion strategies in pediatric cardiac surgery patients: a randomized controlled trial. Intens Care Med 2013; 39: 2011-2019.

46. Willems A, Harrington K, Lacroix J, et al. Comparison of two redcell transfusion strategies after pediatric cardiac surgery: a subgroup analysis. Crit Care Med 2010; 38: 649-656.

47. Lacroix J, Demaret P, Tucci M. Red blood cell transfusion: decision making in pediatric intensive care units. Semin Perinatol 2012; 36: 225-231.

48. Hahn RT, Abraham T, Adams MS, et al. Guidelines for performing a comprehensive transesophageal echocardiographic examination: recommendations from the American Society of Echocardiography and the Society of Cardiovascular Anesthesiologists. Anesth Analg 2014; 118: 21-68.

49. Muhiudeen IA, Roberson DA, Silverman NH, Haas G, Turley K, Cahalan MK. Intraoperative echocardiography in infants and children with congenital cardiac shunt lesions: transesophageal versus epicardial echocardiography. J Am Coll Cardiol 1990; 16: $1687-1695$.

50. Nathan M, Gauvreau K, Liu H, et al. Outcomes differ in patients who undergo immediate intraoperative revision versus patients with delayed postoperative revision of residual lesions in congenital heart operations. J Thorac Cardiovasc Surg 2014; 148: 2540-6. e1-5.

51. Morgan R, Kauffman DF, Doherty G, Sachs T. Resident and attending assessments of operative involvement: Do we agree? Am J Surg 2017; 213: 1178-1185.e1.

52. Talwar S, Choudhary SK, Saxena A, Kothari SS, Juneja R, Airan B. Unidirectional valved patches for closure of septal defects in patients with severe pulmonary hypertension. Ann Pediatr Cardiol 2008; 1: 114-119.

53. Novick W, Sandoval N, Lazorhysynets V, et al. Flap valve double patch closure of ventricular septal defects in children with increased pulmonary vascular resistance. Ann Thorac Surg 2005; 79: 21-28; discussion 21-8.

54. Gilbert C, Gnanapragasam J, Benhaggen R, Novick W. Novel use of extracellular matrix graft for creation of pulmonary valved conduit. World J Pediatr Congenit Heart Surg 2011; 2: 495-501.

55. Choudhary SK, Talwar S, Airan B. Choice of prosthetic heart valve in a developing country. Heart Asia 2016; 8: 65-72.

56. Talwar S, Kumar MV, Bhoje A, et al. Atrial switch procedure in children more than 5 years of age: mid-term results. Interact Cardiovasc Thorac Surg 2016; 23: 694-698.

57. Vricella LA, Dearani JA, Gundry SR, Razzouk AJ, Brauer SD, Bailey LL. Ultra fast track in elective congenital cardiac surgery. Ann Thorac Surg 2000; 69: 865-871. 
58. Shamsuddin A, Nikman A, Ali S, Zain M, Wong A, Corno A. Normothermia for pediatric and congenital heart surgery: an expanded horizon. Front Pediatr 2015; 3: 23.

59. Durandy Y, Hulin S. Intermittent warm blood cardioplegia in the surgical treatment of congenital heart disease: clinical experience with 1400 cases. J Thorac Cardiovasc Surg 2007; 133: 241-246.

60. Mittnacht A, Hollinger I. Fast-tracking in pediatric cardiac surgery - the current standing. Ann Cardiac Anaesth 2010; 13: 92-101.

61. Garg R, Rao S, John C, et al. Extubation in the operating room after cardiac surgery in children: a prospective observational study with multidisciplinary coordinated approach. J Cardiothorac Vasc Anesth 2014; 28: 479-487.

62. Lake CL. Fast tracking in paediatric cardiac anaesthesia: an update. Ann Card Anaesth 2002; 5: 203-208.

63. Connor JA, Ahern JP, Cuccovia B, et al. Implementing a distraction-free practice with the red zone medication safety initiative. Dimens Crit Care Nurs 2016; 35: 116-124.

64. Winters B, Gurses A, Lehmann H, Sexton B, Rampersad C, Pronovost $\mathrm{P}$. Clinical review: checklists - translating evidence into practice. Crit Care 2009; 13: 210.

65. Balachandran R, Nair S, Gopalraj S, Vaidyanathan B, Kumar R. Dedicated pediatric cardiac intensive care unit in a developing country: Does it improve the outcome? Ann Pediatr Cardiol 2011; 4: $122-126$.

66. Meyer E, Lees A, Humphris D, Connell NA. Opportunities and barriers to successful learning transfer: impact of critical care skills training. J Adv Nurs 2007; 60: 308-316.

67. Zeng E. 42 Litre oxygen bag. Retrieved May 26, 2017, from http://www.oxymachines.com/html_products/42-Liter-OxygenBag-413.html.

68. Younus U, Ahmed I, Novick W, Hussain S, Siddiqi R. Role of sildenafil in management of post-operative pulmonary hypertension in children. Eur J Pharm Med Res, 3: 481-484.

69. Walker I. Con: pediatric anesthesia training in developing countries is best achieved by out of country scholarships. Pediatr Anesth 2009; 19: 45-49.

70. Ross R, Delius R, Weinstein S, Rosenkrantz E, Pichardo N, Madera F. Forming a consortium to promote pediatric cardiac care in a developing country. J Pediatrics 2009; 154: 311-312.
71. Kumar RK. Delivering pediatric cardiac care with limited resources. Ann Pediatr Cardiol 2014; 7: 163-166.

72. Uejima T. Medical missions and medical malpractice: the current state of medical malpractice overseas. ASA Newsl 2011; 75: 22-24.

73. Young N, Everett J, Simsic J, et al. A stepwise model for delivering medical humanitarian aid requiring complex interventions. J Thorac Cardiovasc Surg 2014; 148: 2480-2489.e1.

74. Royal College of Nursing. Indemnity scheme. Retrieved May 26, 2017, from https://www.rcn.org.uk/get-help/indemnity-scheme.

75. Nguyen N, Leon-Wyss J, Iyer K, Pezzella A. Paediatric cardiac surgery in low-income and middle-income countries: a continuing challenge. Arch Dis Child 2015; 100: 1156-1159.

76. Gaies M, Jeffries H, Jacobs J, Laussen P. Measuring quality and outcomes in pediatric cardiac critical care. Prog Pediatr Cardiol 2012; 33: 33-36.

77. Jacobs JP, Jacobs ML, Austin EH, et al. Quality measures for congenital and pediatric cardiac surgery. World J Pediatr Congenit Heart Surg 2012; 3: 32-47.

78. Jenkins K, Castañeda A, Cherian KM, et al. Reducing mortality and infections after congenital heart surgery in the developing world. Pediatrics 2014; 134: e1422-e1430.

79. Balachandran R, Kappanayil M, Sen A, et al. Impact of the international quality improvement collaborative on outcomes after congenital heart surgery: a single center experience in a developing economy. Ann Cardiac Anaesth 2015; 18: 52-57.

80. Schidlow DN, Jenkins KJ, Gauvreau K, et al. Transposition of the great arteries in the developing world: surgery and outcomes. J Am Coll Cardiol 2017; 69: 43-51.

81. Jacobs JP, Jacobs ML, Maruszewski B, et al. Current status of the European Association for Cardio-Thoracic Surgery and the Society of Thoracic Surgeons Congenital Heart Surgery Database. Ann Thorac Surg 2005; 80: 2278-2283; discussion 2283-4.

82. Riviello R, Ozgediz D, Hsia RY, Azzie G, Newton M, Tarpley J. Role of collaborative academic partnerships in surgical training, education, and provision. World J Surg 2010; 34: 459-465.

83. Axelrod D, Klugman D, Wright G, et al. One hundred useful references in pediatric cardiac intensive care: the 2012 update. Pediatr Crit Care Med 2013; 14: 770-785. 